\title{
Una Aplicación de la Metodología de Redes Sociales a la Investigación Etnográfica
}

\author{
Laura Teves $^{1}$ \\ Marta Crivos \\ María Rosa Martínez \\ Cynthia Sáenz \\ Universidad Nacional de La Plata- Argentina
}

\begin{abstract}
En este trabajo nos proponemos utilizar la metodología de redes sociales como estrategia para el análisis de información relativa al dominio de las actividades de subsistencia -caza, recolección, horticultura, producción de artesanías y otras- en una comunidad aborigen Mbyá-Guaraní, integrada actualmente por 157 personas, en la Reserva de Usos Múltiples del "Valle del Cuñapirú", Misiones, Argentina. El estudio comenzó con el diseño de una encuesta etnográfica cuyos ítem permitieron obtener datos sobre todas las actividades que transectan las unidades domésticas y que definen vínculos entre los actores involucrados en las diferentes tareas y sus etapas de desarrollo, tanto dentro como fuera de la comunidad. De este modo iniciamos el análisis de redes sociales, aplicando las medidas de centralidad, con el propósito de visualizar los patrones de interacción emergentes del modo de subsistencia MbyáGuaraní.
\end{abstract}

\section{Introducción}

La discusión teórica y metodológica actual impone un análisis diferente de los datos en el campo de la etnografía. Esto implica abordar estrategias metodológicas que permitan optimizar los recursos analíticos del etnógrafo y abordar instancias comparativas entre las poblaciones estudiadas.

El estudio de redes surge en nuestra investigación como una estrategia para pensar la relación del hombre con la naturaleza, a través de la descripción de las conductas grupales que conducen a los Mbyá Guaraní a una utilización sostenida de su medio ambiente. A esto se suma la creación de la Reserva Privada de Usos Múltiples que establece un programa de acceso y manejo de las áreas naturales, con lo cual se plantea la necesidad de establecer hasta qué punto estas políticas afectarían el estilo de vida de las comunidades aborígenes y particularmente las estrategias económicas ${ }^{2}$ base de la alimentación y

1 Iteves@museo.fcnym.unlp.edu.ar

2 La designación estrategias económicas y las actividades de subsistencia serán

http://revista-redes.rediris.es 
reproducción del grupo y cuáles de las actividades de subsistencia serían las que sufrirían mayor impacto.

El estudio de redes surge como adecuado a la consideración de esta problemática relevante al sostenimiento de la tierra y sus recursos, así como también puede aportar claridad al debate generado por el cruce de intereses sobre el tema. La toma de decisiones acerca del manejo del predio debe tener en cuenta estudios diagnósticos sobre los modos de ocupación actual del territorio que dan sustento a la forma de vida de las comunidades Mbyá Guaraní.

\section{La investigación etnográfica en la zona}

El sub-proyecto "Estudio etnográfico en el Valle del Cuñapirú" dentro del Proyecto "Caracterización antropológica del modo de vida. Implicancias teórico- empíricas de las estrategias de investigación etnográfica", es llevado a cabo por un equipo integrado por antropólogos: investigadores, docentes y alumnos pasantes en el Valle del Cuñapirú, Misiones, Argentina. Desde 1994 la Comisión de Medio Ambiente del Centro de Estudiantes de la Facultad de Ciencias Naturales y Museo de nuestra Universidad, realiza viajes de campaña a la zona. De este modo se combinan un objetivo pedagógico (Escuela de campo) con la posibilidad de iniciar estudios interdisciplinarios que integran Cátedras y Equipos de investigación de diferentes disciplinas de las Ciencias Naturales, al estudio intensivo del área de mayor biodiversidad de nuestro país. En el marco de este emprendimiento, a partir del año 1996 y hasta la actualidad se realizan en forma periódica y sistemática relevamientos etnográficos en las comunidades Mbyá- Guaraní.

Estas dos comunidades asentadas en una área de 6.144 hectáreas están hoy bajo el régimen legal de una Reserva Privada de Usos Múltiples perteneciente a la UNLP en convenio con el Ministerio de Ecología de la provincia de Misiones. (ver Anexo 1). 
El estudio etnográfico se integra como un enfoque específico en distintos proyectos interdisciplinarios en el área conformándose un equipo de biólogos y antropólogos interesados en abordar distintas problemáticas derivadas de la ocupación humana de un medio ambiente de Selvas Tropicales. De este modo se espera aportar elementos de juicio a planes de manejo del área protegida tendientes al auto-sostenimiento y conservación del medio ambiente cultural y natural de estos territorios que integran la última porción del "corredor verde" de la selva amazónica en Argentina.

En este contexto consideramos prioritario generar un espacio para el estudio etnográfico del modo de vida de los grupos residentes en el área, poniendo especial énfasis en la consideración de sus interacciones con el medio ambiente natural. Dadas las características culturales de los grupos en estudio en particular su patrón de movilidad, sus interacciones con el medio natural involucran desplazamientos permanentes a lo largo de un circuito (que actualmente atraviesa una gran porción del territorio de Paraguay, sudeste de Brasil y recientemente el noreste de Uruguay).

Se opta por el registro etnográfico de las actividades de subsistencia como contextos de tomas de decisión rutinarias que integran las interacciones individuales (nivel micro) con las estructuras de la sociedad (nivel macro). De este modo el trabajo etnográfico nos conduce desde las conductas concretas a lo que emerge de ellas como un patrón de organización diferente, representado en la estructura de red.

Las actividades de subsistencia de las comunidades en estudio incluyen en primer término, la horticultura - mediante el sistema de roza y quema- cuyos cultivos más importantes son el maíz, batata, mandioca, maní, zapallo, sandía y poroto. En la actualidad han incorporado algunas plantas frutales: duraznos y cítricos. También practican la caza. Capturan las aves imitando su canto o con trampas. Cazan pecarí chico, armadillo, coatí, jabalí y venado. La tecnología de la caza incluye el uso del arco y la flecha (cada vez menos frecuente) y la incorporación paulatina de armas de fuego. En el caso de la pesca utilizan redes, anzuelos, trampas y a su vez disponen de ciertas especies vegetales 
ictiotóxicas. Si bien la recolección se realiza a lo largo de todo el ciclo anual, es el verano la época en que abundan ciertos recursos del "monte" tales como miel y frutos silvestres. La producción de artesanías comprende la manufactura de tallas en madera, cestería y collares. Asimismo realizan trabajo temporario en las Colonias ${ }^{3}$ : desmonte, carpida, desyerbe y otras tareas en las plantaciones de yerba mate, té y tabaco (Crivos et al, 1999).

\section{METODOLOGI A}

El material obtenido en las cuatro primeras campañas junto con los Protocolos del Programa de la Union Europea The Future Tropical Rain Forest Peoples ${ }^{4}$, para el estudio de pueblos de las Selvas Tropicales y aplicadas en grupos del Caribe, África Central y SE del Pacífico, permitieron diseñar una encuesta etnográfica orientada al relevamiento de datos focalizando sobre las interacciones intra e intercomunitarias involucradas en la subsistencia de los Mbyá.

Los principales ítem contemplados en la encuesta fueron:

1. Identidad del individuo y parentesco. Movilidad individual y familiar.

2. Actividades económicas: horticultura, recolección, caza, pesca, artesanías, actividades en la unidad habitacional.

3. Autopercepción del encuestado: evaluación del informante sobre su situación personal en la comunidad de Kaaguy Poty al momento de la encuesta.

4. Percepción del encuestado sobre la relación entre los Mbyá y sectores externos a la comunidad en estudio: médicos- enfermeros, policías, maestros, colonos, población urbana de Aristóbulo del Valle, otros grupos Mbyá de Misiones y países limítrofes (Paraguay y Brasil).

\footnotetext{
3 “Colonia" designa a una unidad de producción agrícolo-ganadera, generalmente de pequeña extensión.

${ }^{4}$ http//lucy.ukc.ac.uk/Rainforest/index.html
} 
Para este trabajo se seleccionó sólo la información que responde al punto 2 . Este ítem de la encuesta incluye sub-ítem que permitieron recabar información acerca de las relaciones entre los individuos en las distintas etapas de cada actividad: quién/es las realizan, quién toma la iniciativa, quién obtiene, transporta, procesa y almacena el producto de la actividad. En cuanto a los productos obtenidos para cada actividad quién/es lo/s consume/n, distribuye/n, comercializa/n o intercambia/n. dentro y fuera de la comunidad.

Se realizaron 23 encuestas a los responsables de cada unidad habitacional, $\mathrm{UH}^{5}$. El encuestador cargó los datos en planillas mientras, simultáneamente, se grabó la entrevista. La mayor parte de las preguntas las contestaron los hombres, pero estos dieron participación a sus esposas para aquellas respuestas referidas a las actividades femeninas. Se obtuvieron 28 horas de grabación.

Este material fue procesado en el Laboratorio realizándose síntesis de contenido de la totalidad del registro grabado, la información referida a las actividades económicas se volcó en hojas de Excel. Se cargaron 11 planillas bajo el rótulo de Horticultura, que agrupan las siguientes etapas: desmonte, carpida, macheteada, roza, provisión de semillas, siembra, procesamiento, transporte, almacenamiento y distribución de la cosecha; Caza; Pesca; Recolección: materias primas para artesanías, miel, frutos; Actividades en la unidad habitacional: preparación de la comida, lavado de ropa, construcción de la vivienda, mantenimiento del fuego; Artesanías: tallas, collares y cestería (Anexo 2).

En un etapa posterior se controló la calidad de la información, eliminando los datos resultantes de las respuestas inducidas por el encuestador.

A partir del corpus de datos, compuesto por todos lo lazos entre pares o díadas, intentamos obtener la red completa de relaciones económicas de la población.

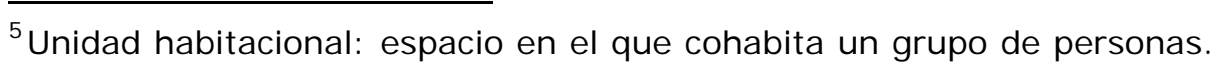


Se cargaron matrices de actor ${ }^{6}$ por actor y de actor por evento ${ }^{7}$ en Excel y se procesaron en UCINETV ${ }^{8}$ :

Como base para determinar el tamaño de la población, tomamos el censo completo correspondiente al año 1998 de Kaaguy Poty, al cual se le agregaron nodos que corresponden a instituciones, localidades y personas externas a la comunidad con los cuales los miembros de esta reconocen vínculos.

El censo poblacional arrojó un número de 157 personas, de las cuales 100 se encuentran involucradas en al menos una actividad y 57 no participan en ninguna actividad (36,3\% de la población). En referencia a los vínculos con el afuera se presentó el caso tanto de instituciones, localidades y personas que no pertenecen a la población estable para dicho censo, pero si aparecen mencionados en al menos una actividad: $\mathrm{N}=22$. Sumando los individuos tanto internos como externos a la comunidad y restando los individuos que no participan en ninguna actividad trabajamos con un $\mathrm{N}=122$.

Sobre una población económicamente activa de 122 nodos se construyeron las 6 matrices para cada actividad conteniendo sólo los actores involucrados en cada una de ellas. Ninguna de las matrices alcanza un $\mathrm{N}=122$, es decir ninguna de las actividades involucra a todos los actores.

Los primeros cálculos arrojan los siguientes resultados (Anexo 3):

- Las personas que no participan en ninguna actividad son 57; . Niños varones: 26; Niñas mujeres: 21; Varones adultos: 3; Mujeres adultas: 7.

- El porcentaje de población estable activa es el $63.7 \%$ del total de habitantes de Kaaguy Poty. Son 100 individuos, de los cuales 53 son femeninos y 47 masculinos.

\footnotetext{
${ }^{6}$ Miembros de la Comunidad Mbyá Guaraní de Kaaguy Poty e instituciones, localidades y personas vinculados a ellos por las actividades económicas

7 Actividades económicas Mbyá-Guaraní

${ }^{8}$ Agradecemos a Roberta Chase y Steve Borgatti el habernos facilitado gratuitamente la licencia del software UCINET5 Versión 5.74 con el que pudimos analizar los datos presentados en este trabajo. support@analytictech.com
} 
- La distribución de la población para cada actividad por sexo y edad muestra que:

La actividad en la Unidades Habitacionales presenta el porcentaje mas alto de individuos involucrados, tanto niños como adultos de ambos sexos de todos los grupos etarios.

El porcentaje más alto de participación de las mujeres se establece en las actividades en las UH, seguida por la Horticultura; Artesanías; Recolección; Pesca y Caza.

La participación de los niños en las actividades en las UH alcanza el doble que en la Horticultura, disminuyendo la proporción en Artesanías, Caza, Pesca y Recolección en ese orden. Las niñas participan en mayor medida en las actividades de las UH y la Horticultura. Los niños varones son los únicos que participan en la Caza.

Los varones adultos tienen un alto porcentaje de participación en todas las actividades.

\section{RESULTADOS SOBRE LA ESTIMACIÓN DE LAS MEDIDAS DE CENTRALI DAD}

Calculamos las tres medidas de centralidad de Freeman: grado (degree), grado de intermediación (betweenness) y grado de cercanía (closeness), para cada una de las matrices construidas.

Consideramos que la estimación de estas medidas de centralidad es adecuada para el análisis de nuestros datos porque nos permite, inicialmente, explorar la estructura de la organización socio-económica en base a cómo se configuran las relaciones para cada una de las actividades seleccionadas.

Los cálculos de las medidas de centralidad se realizaron sobre 7 matrices:

Matriz Modo 2: se cargaron 6 matrices construidas sobre la variable tipo de actividad económica, en cuyas filas se colocaron los 23 informantes y en las columnas los 122 actores. Fueron eliminados de las columnas aquellos actores 
que no participan en la actividad detallada. Las matrices quedaron conformadas del siguiente modo: Matriz 1: Horticultura $=23 * 73$; Matriz 2: Recolección $=23 * 48$; Matriz 3: Artesanías $=23 * 57$; Matriz 4: Actividad en la Unidad Habitacional $=23 * 81 ;$ Matriz 5: Caza $=23 * 45 ;$ Matriz 6: Pesca $=$ $23 * 40$.

Matriz de afiliación: se cargaron todos los actores involucrados en todas las actividades económicas, dentro y fuera de la comunidad de Kaaguy Poty. Matriz 7: Actor por Evento: 122*6. Se obtuvo una matriz cuya variable medida fue la participación de cada individuo en cada una de las actividades económicas seleccionadas para el grupo.

El resultado de los cálculos nos permite establecer para la actividad horticultura:

- En esta actividad participan 73 nodos: varones mayores de 15 años (30 nodos), mujeres mayores de 15 años ( 26 nodos), niñas menores de 15 años ( 9 nodos) y niños menores de 15 años ( 4 nodos). Se incluyen además referencias a personas, instituciones o localidades externas al grupo (4 nodos).

- Esta actividad incluye tareas que se desarrollan durante todo el ciclo anual, implicando una alta frecuencia de interacciones entre los nodos.

- Este cálculo muestra la relación con la localidad urbana más próxima a la comunidad indígena (Aristóbulo del Valle), con el grado de centralidad más alto. Introduciendo así el factor contacto con el afuera como un vínculo importante para la realización de la horticultura.

- Dentro del grupo, los nodos con posición central en la red son tres varones adultos pertenecientes a la comunidad. Como atributos relevantes a su interpretación: los tres desempeñan roles de alta jerarquía política (cacique actual y ex cacique) y pertenecen a la misma familia extensa ${ }^{9}$.

\footnotetext{
${ }^{9}$ Familia Extensa (Extended Family): Compuesta por dos o más familias nucleares unidas por lazos consanguíneos. Schusky E. 1965. Manual de Análisis de Parentesco. Tomo I. (traducción)
} 
- Estos mismos individuos presentan los valores más altos de intermediación para la horticultura: son quienes toman decisiones respecto a la asignación de tareas en distintas instancias de esta actividad.

- Respecto a la actividad hortícola el análisis muestra que no hay conectividad.

El resultado de los cálculos nos permite establecer para la actividad recolección:

- Participan 48 nodos: 21 varones adultos, 4 niños, 22 mujeres adultas y ninguna niña. Se incluye además una referencia a personas, instituciones o localidades externas al grupo. Como atributo relevante a su interpretación: Estas personas pertenecen a 6 familias de las 8 que integran la comunidad. Dos grupos compuestos por 3 de estas familias son los que se organizan para la obtención de alimentos y la obtención de materias primas para la realización de artesanías.

- Para los valores de centralidad en esta matriz es importante destacar que las mujeres adultas tienen los valores mas altos, y coinciden con los valores de intermediación en tres de los casos.

- Respecto a esta actividad el análisis muestra que no hay conectividad.

En el caso de las actividades en la Unidad Habitacional:

- Participan 81 nodos: 16 niñas, 27 mujeres adultas, 12 niños y 23 varones adultos. Se incluyen además tres referencias a personas, instituciones 0 localidades externas al grupo.

- Para las actividades al interior de las UH se establece una correspondencia entre los individuos que integran la red y los espacios de habitación. Se identificaron 15 grupos de nodos, cada uno de los cuales se corresponde con una o mas unidades habitacionales. Como atributo relevante a su interpretación: cada grupo corresponde a una familia extensa. Es importante destacar que las unidades habitacionales ocupadas únicamente por ancianos son sostenidas en todos los casos por alguno de estos 15 grupos.

- Se identificaron 7 nodos con el más alto grado de centralidad. En su mayoría son varones adultos, a excepción de dos de ellos que son niños. Es importante 
destacar que en esta actividad la mayoría de los nodos involucrados son mujeres. El hecho que los nodos centrales sean varones puede deberse a que son quienes realizan tareas vinculadas a la construcción de la totalidad de las viviendas de la comunidad.

Con respecto a la actividad artesanías los cálculos nos permiten establecer que:

- Participan 57 nodos: 5 niñas, 22 mujeres adultas, 2 niños y 20 varones adultos, además de 8 personas, instituciones o localidades externas al grupo.

- Los valores con mas alto grado de centralidad están representados por nodos externos a la comunidad (personas, instituciones o localidades). Esta relación con el afuera esta señalando la relevancia de la instancia de comercialización de los productos obtenidos en la actividad.

- Los valores mas altos de intermediación coinciden con los valores mas altos de centralidad, lo que esta demostrando que en la red no hay intermediarios, sino que cada uno de los nodos se relaciona directamente con alguno de los nodos centrales en la red.

- El grado de cercanía no puede ser calculado, debido a que técnicamente esta red no esta conectada.

Para la actividad de la caza participan 45 nodos: 15 mujeres adultas, 5 niños, 25 varones adultos, y ninguna niña.

- Los valores mas alto de centralidad para esta actividad se corresponden con personas adultas de ambos sexos. El rol de las mujeres en esta actividad se centra en el procesamiento y distribución de los productos de la caza.

- Se identificaron 7 grupos de individuos vinculados por lazos de parentesco, padre del padre-padre-hijo-sobrino (Anexo 4.1).

- Los valores mas altos de grado e intermediación corresponden a los mismos nodos. Es de destacar que ninguna mujer intermedia en la actividad de caza.

En la actividad de la pesca participan 40 nodos: 11 mujeres adultas, 2 niñas, 23 varones adultos y 4 niños. 
- Los valores de centralidad más altos son para 10 nodos, de los cuales 3 son mujeres adultas y 7 son varones adultos, que se corresponden con 2 familias extensas.

- Los valores de intermediación coinciden con los valores más altos de centralidad en 3 casos.

\section{CONCLUSIONES}

Una descripción de la red general para todas las actividades nos permite visualizar las relaciones tanto entre los miembros de la comunidad como entre éstos y el afuera. Observamos como patrón que los individuos centrales no superan las 4 o 5 personas, y coinciden para todas las actividades. Todos ellos reciben la denominación nativa de Karai, este término es utilizado para designar a los adultos masculinos que ha conformado una familia. En el caso de las mujeres, se utiliza el término Kuña Karai, con el mismo sentido. El término Karai en su aplicación en diferentes contextos alude a madurez, espiritualidad, sabiduría y poder, atributos que habilitan a quienes los poseen hombres o mujeres- a realizar tareas indelegables a los jóvenes ${ }^{10}$.

Entre los pocos individuos centrales y la mayoría de la población aparecen cuatro individuos que actúan como intermediarios. Estas personas son jefes de familia extensa que involucran a distintas familias nucleares, las cuales ocupan varias UH y tienen autonomía en la organización de cada actividad económica. Estas personas también podrían ser designadas como Karai y Kuña Karai y con las designaciones Tuja-Mbyté y Guaymi Mbyte por la pertenencia al grupo etario de adultos mayores de alrededor de 45 a 50 años. Los Tuja quedan exentos del trabajo fuera de la comunidad, en las colonias, ocasionalmente trabajan en la chacra, van al monte a cazar y a buscar recursos vegetales que

10 Estas características se señalan para grupos cuya subsistencia se basa en recursos análogos - horticultura, caza, pesca y recolección- como atributos de los notables. "Tal vez sea posible definir a los notables estadísticamente: se trata de aquellos hombres que con más frecuencia que otros inician las acciones a las que se adhiere un grupo. Un individuo no interviene con frecuencia en la toma de decisiones por ser un notable; es un notable porque interviene con frecuencia en la toma de decisiones" (Rappaport, 1968: 30). 
utilizan en actividades médicas y artesanales o colectan yuyos que crecen en las cercanías de su vivienda o en lugares a los que les es fácil acceder, sin demasiado esfuerzo físico o largas caminatas. (Anexo 4.2).

Un tercio de la población estable pero no activa de KP está representado por un grupo mayoritario de individuos cuyas edades varían entre 0 y 14 años y un grupo de adultos entre 16 y 52 años. Una posible explicación de este hecho es que los individuos incluidos en este último rango etáreo permanecen en distintos períodos del año fuera de la comunidad realizando trabajo asalariado, en particular en la tarefa ${ }^{11}$.

Consideramos que la red de actividades económicas no es la suma de individuos aislados sino que se compone de unidades autónomas pero vinculadas. Al interior de estas unidades las relaciones son más frecuentes e intensas. Los individuos que las conforman son en parte co-residentes ${ }^{12}$, y los vinculan lazos de parentesco consanguíneo y afinidad.

De este modo, el análisis de redes sociales nos conduce a la noción de unidad doméstica (UD). Definida como unidad compleja que incluye tres componentes: social (grupo de personas unidas o no por lazos de parentesco y que comparten la residencia), espacial (el espacio físico que habitan), y económico (actividades de subsistencia del grupo realizadas total o parcialmente en ese ámbito) ${ }^{13}$, resulta operativa a nuestro análisis etnográfico de redes sociales, tanto a nivel teórico como metodológico.

La red no tiene un alto grado de cohesión a nivel de los nodos de individuos, pero las unidades domésticas que la componen sí están integradas, representan grupos diferenciados que coinciden con familias extendidas cuya articulación está dada por los jefes de estas familias. De estos nodos centrales

11 En el caso de los cultivos industriales o plantaciones, se contrata mano de obra temporaria, en calidad de trabajadores a destajo, particularmente en la cosecha

12 Corresidencia (corresidence): "Contigüidad local o territorial". La residencia compartida de grupos parentales en UH o agrupaciones de UH puede llevar a que "se confundan los lazos de corresidencia con los de parentesco". Schusky, E. 1965. Manual de Análisis de Parentesco. Serie Monografías Antropológicas. Tomo 1. (traducción)

${ }^{13}$ Crivos, M. y .R. Martínez, 1996 
depende la red para la conexión con los niveles intra e inter comunitarios: Instituciones nacionales y provinciales; consejo de caciques y relaciones políticas con otras comunidades; y particulares (Anexo 4.3).

Analizar las proyecciones a macro escala del patrón de organización social ligado a la subsistencia de la comunidad de Kaaguy Poty constituye una vía para la interpretación de la red y el objetivo a abordar en futuras etapas de esta investigación. 


\section{BI BLI OGRAFI A}

Batagelj, Vladimir and Andrej Mrvar. 2001. Pajek 0.77. Copyright ( 1996. http://wlado.fmf.uni-lj.si/pub/networks/pajek/

Borgatti, S.P., M.G. Everett and L.C. Freeman. 1999. UCINET V for Windows: Software for Social Network Analysis. Natick: Analytic Technologies.

Crivos; Marta y María Rosa Martínez. 1996. Estudio etnográfico de los Mbyáguaraní. Relación hombre- medio. Aristóbulo del Valle, Provincia de Misiones. Informe presentado a la Facultad de Ciencias Naturales y Museo de la Universidad Nacional de La Plata. Argentina.

Martínez, María Rosa, Marta Alicia Crivos y Carolina Remorini. 2002. Etnografía de la Vejez en Comunidades Mbyá-Guarani, Provincia de Misiones, Argentina. Ponencia presentada al Congreso 3ra. Conferenza Internazionale Di Antropologia e Storia della Salute e delle Malattie "Vivere e 'Curare'la vechiaia nel mondo". Génova, I talia.

Teves, Laura y colaboradores. 1997. Prospección Etnográfica en el Valle del Cuñapirú, Misiones. Actas de las J ornadas de Jóvenes Investigadores. Instituto Nacional de Antropología y Pensamiento Latinoamericano. Buenos Aires

Teves, Laura. 1998. Household Unit as an analytical unit in ethnographic research. Session Ethnographic Methodology: New Trends on the Record and Description of Life Styles. Actas del Congreso Internacional de Ciencias Antropológicas y Etnológicas, Williamburg, USA.

Hanneman, Robert A. Introducción a los Métodos del Análisis de Redes Sociales. http://wizard.ucr.edu/ rhannema/networks/text/textindex.html

Molina, J osé Luis. 2000. II Taller de Introducción al Análisis de Redes Sociales con UCI NET IV. http://members. es. tripod. de/redes/taller.htm

Molina, José Luis. 2000. El análisis de redes sociales. Ediciones Bellaterra. Barcelona, España. 
Rappaport, Roy A. 1968. Cerdos para los antepasados. El ritual en la ecología de un pueblo en Nueva Guinea. Siglo XXI de España editores S.A.

Requena Santos, Félix. 1989. El concepto de red social. Revista Española de Investigaciones Sociológicas, Nro. 48, octubre-diciembre, pp 137- 152.

Schweizer, Thomas. 1997. Embeddedness of Ethnographic Cases. A Social Networks Perspective en Current Anthropology, vol. 38, Nro. 5, December, University of Chicago Press.

Schweizer, Thomas and Douglas White, eds. 1998. Kinship, Networks, and Exchange. Structural Analysis in the Social Sciences Series, New York and Cambridge: Cambridge University Press.

White, Douglas. 2001. Developing Theory of Network Structure/ Dynamics and Ethnographic Applications. NSF Proposal. 
Anexos. 1- Mapa de la zona de estudio

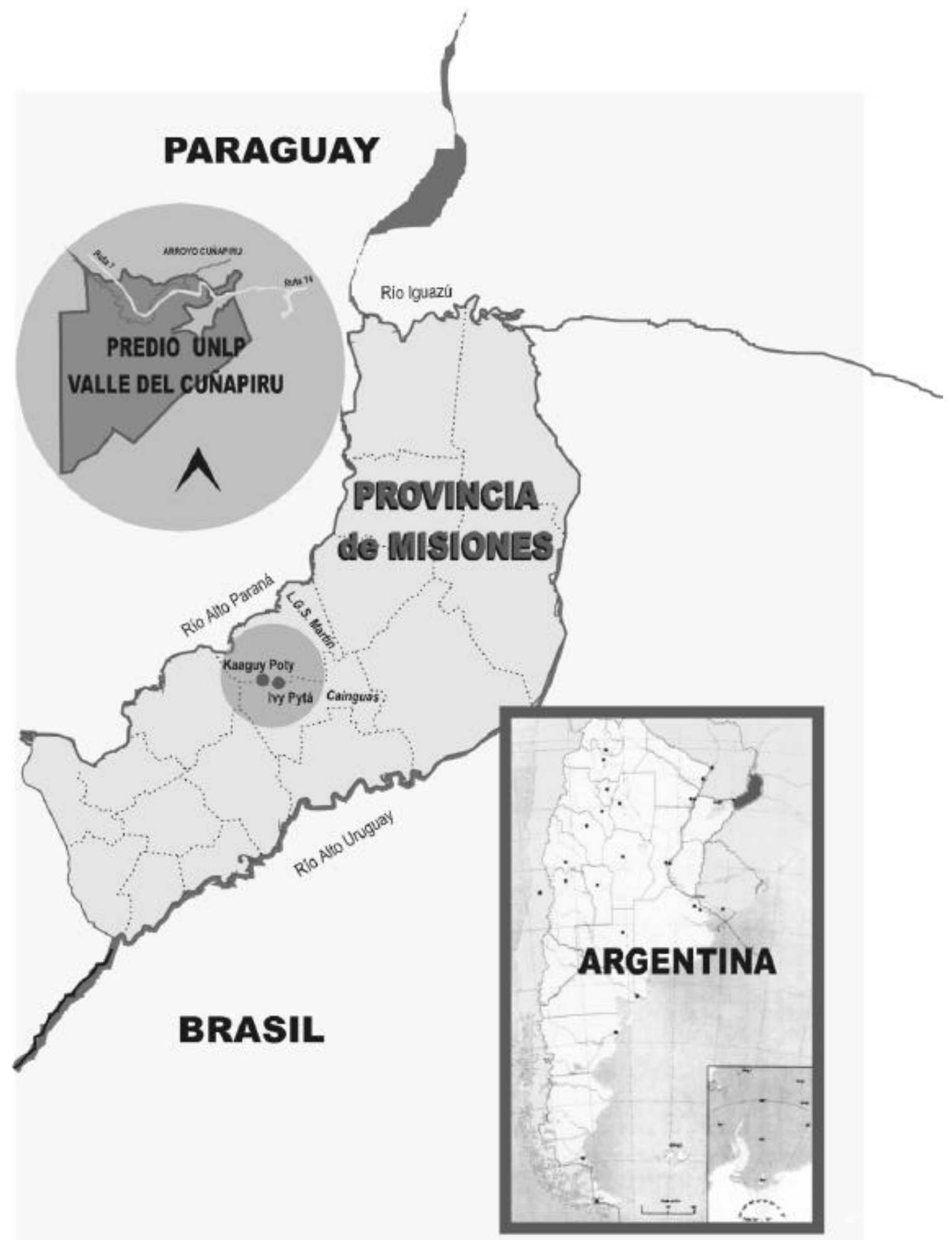




\section{2- Planilla con el primer análisis de los datos de redes}

\section{CAZA}

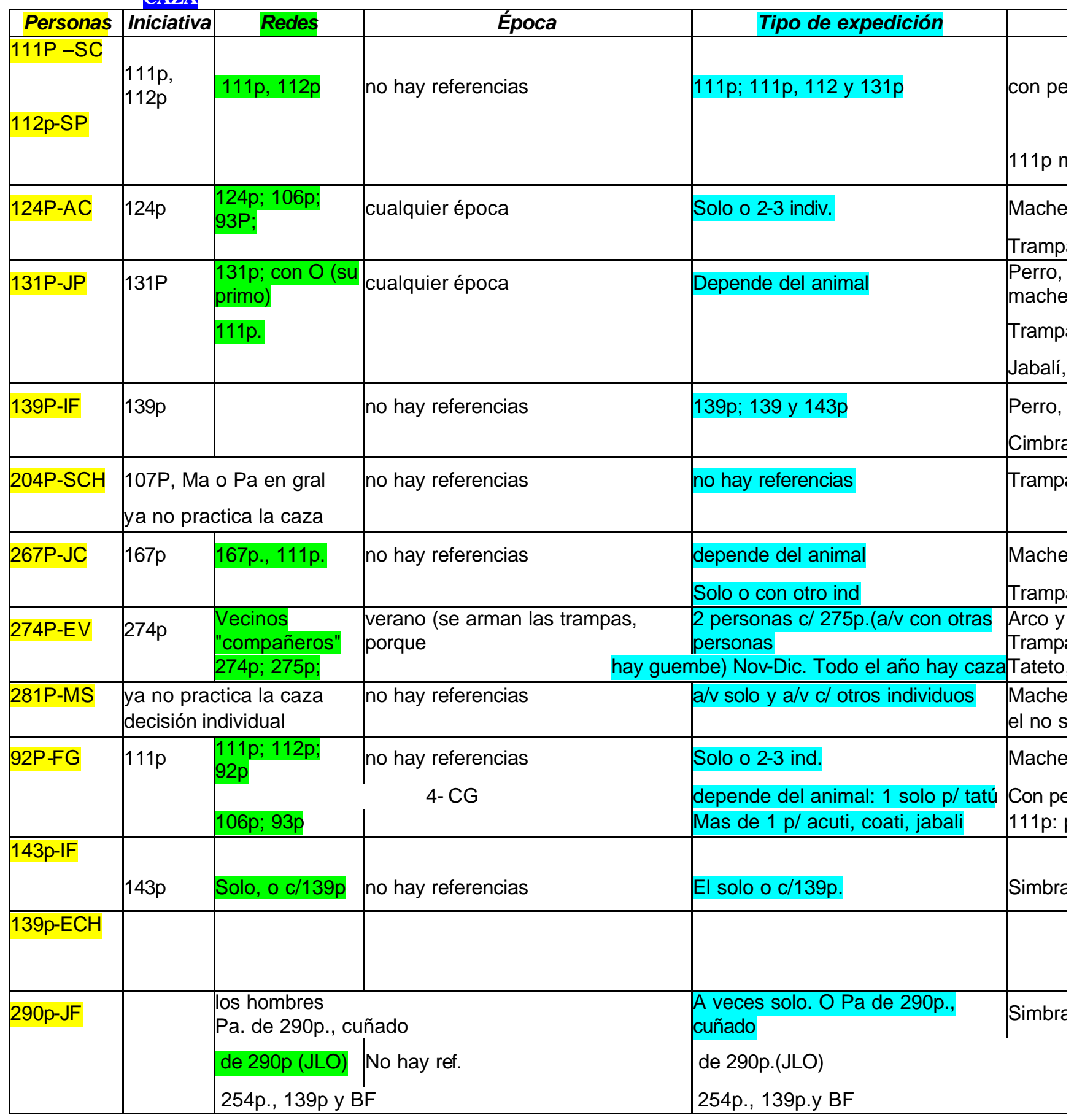




\section{3- Tablas y porcentajes sobre las actividades económicas en la} población de Kaaguy Poty

\begin{tabular}{|l|c|c|c|c|c|c|c||}
\hline \multicolumn{1}{|c|}{ Población } & Recolección & Artesanías & Caza & Pesca & AUH & Horticultura \\
\hline Femenino & 22 & 26 & 15 & 13 & 43 & 35 \\
\hline Masculino & 23 & 20 & 27 & 26 & 35 & 29 \\
\hline Externos & 3 & 11 & 3 & 1 & 3 & 9 \\
\hline Ausentes & 74 & 65 & 76 & 82 & 41 & 49 \\
\hline
\end{tabular}
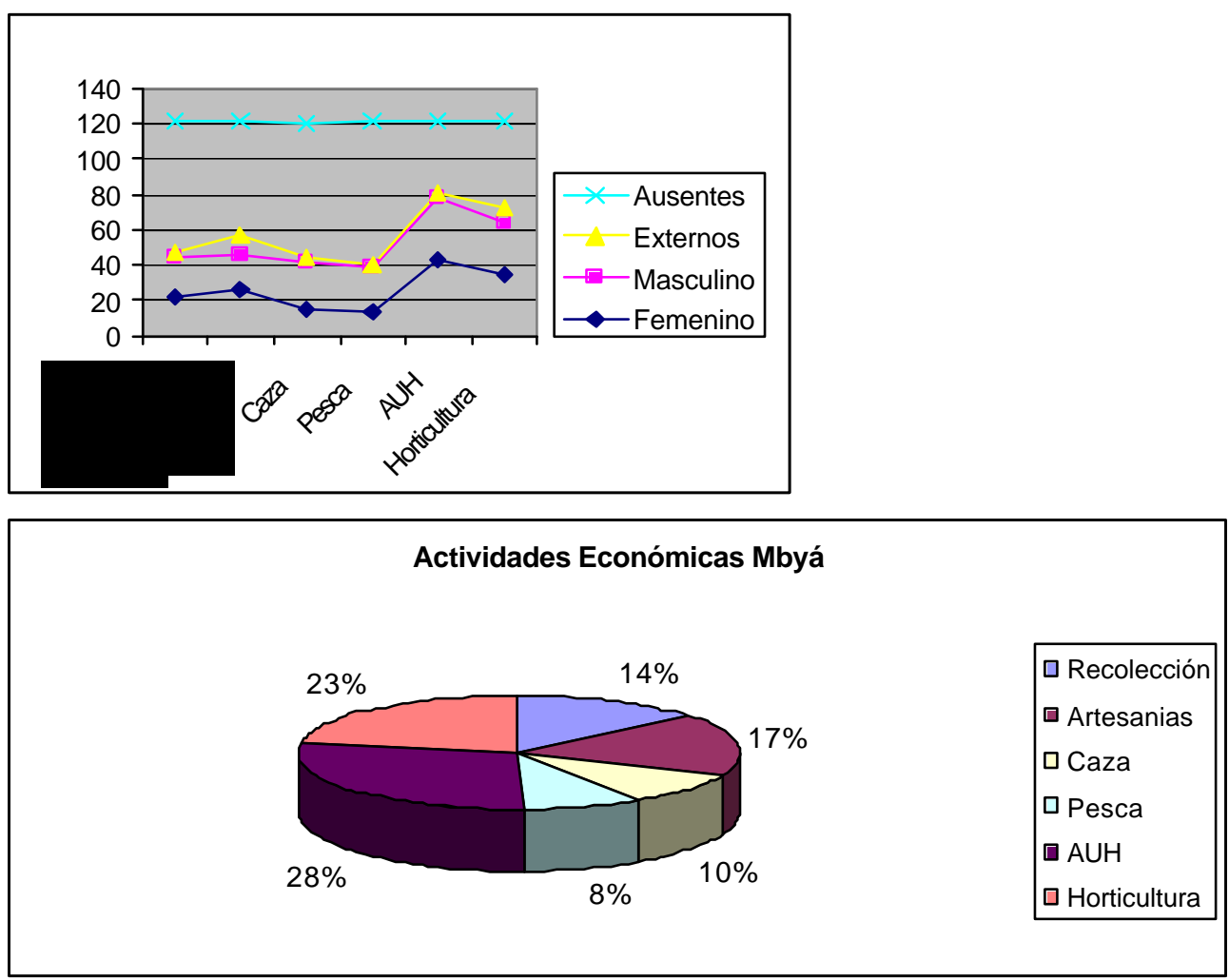


\begin{tabular}{|c|c|c|c|c|c|c|c|}
\hline Población & Recolección & Artesanías & Caza & Pesca & AUH & Horticultura \\
\hline \hline Femenino Niña & 0 & 5 & 0 & 2 & 16 & 9 \\
\hline \hline Masculino Niño & 4 & 2 & 5 & 4 & 12 & 4 \\
\hline \hline Femenino Adulto & 22 & 21 & 15 & 11 & 27 & 26 \\
\hline \hline Masculino Adulto & 21 & 18 & 25 & 23 & 26 & 30 \\
\hline
\end{tabular}

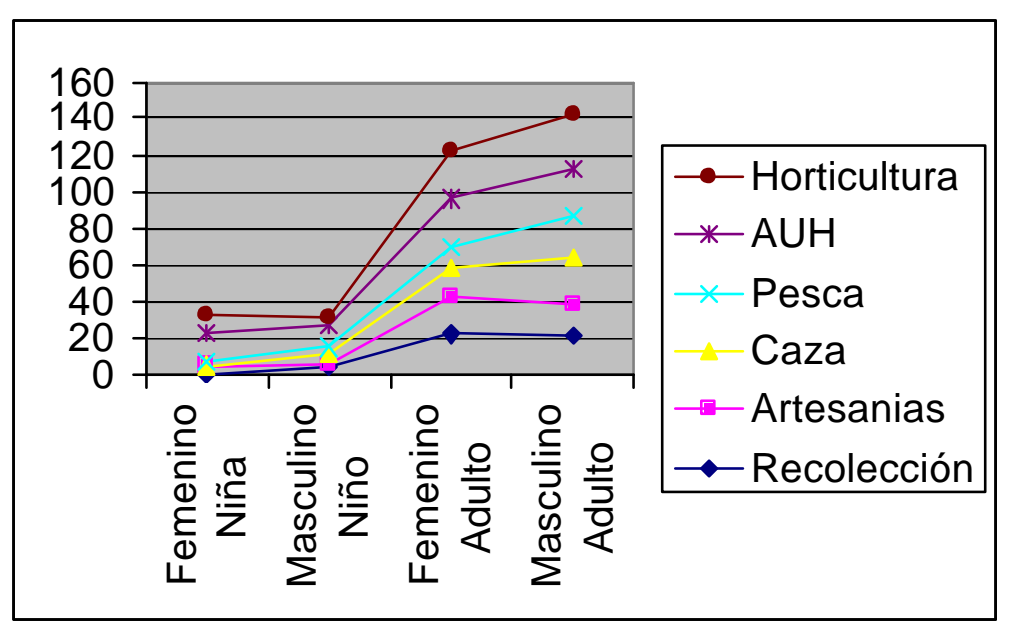




\section{4- Gráficos de redes}

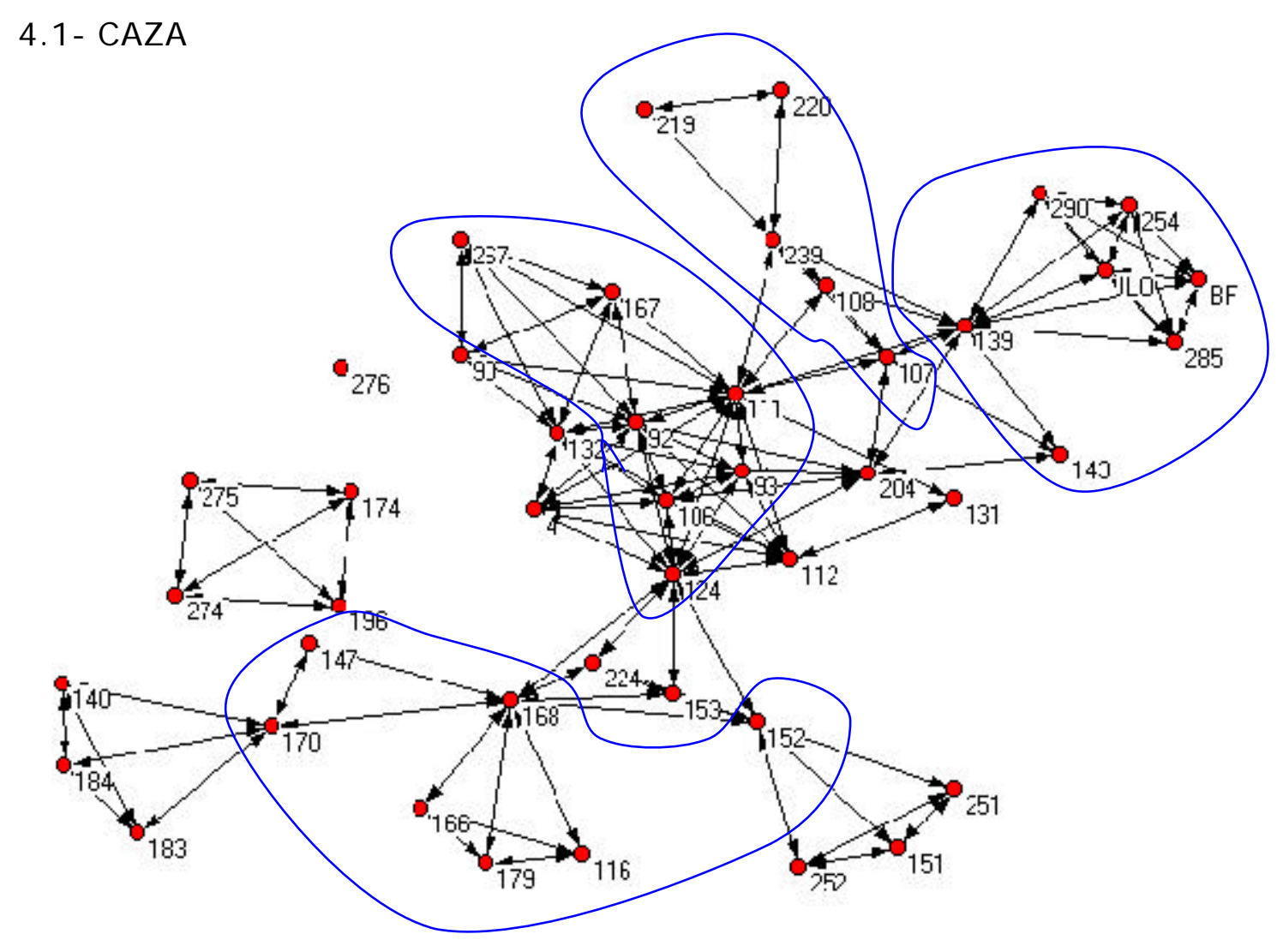

Referencias

Padre del Padre $\longrightarrow$ Padre $\longrightarrow$ Hijos 
4.2- Horticultura

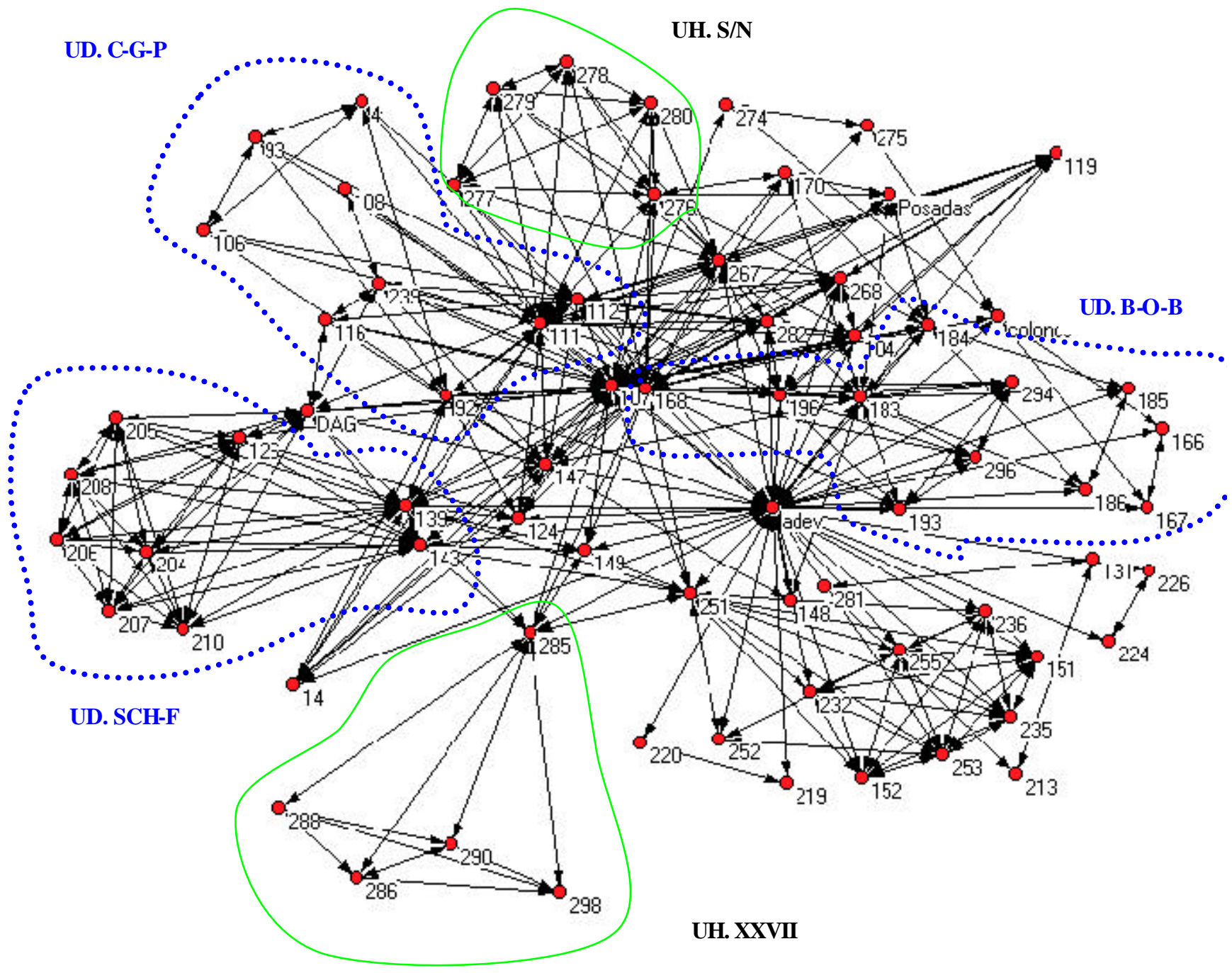

Referencias:

UD. SCH-F.: Familia extensa

UD B-O-B Familia extensa

UD C-G-P: Familia extensa

UH S/N: Familia nuclear

UHXXVII: Familia nuclear 
4.3- Actividades en las Unidades Habitacionales

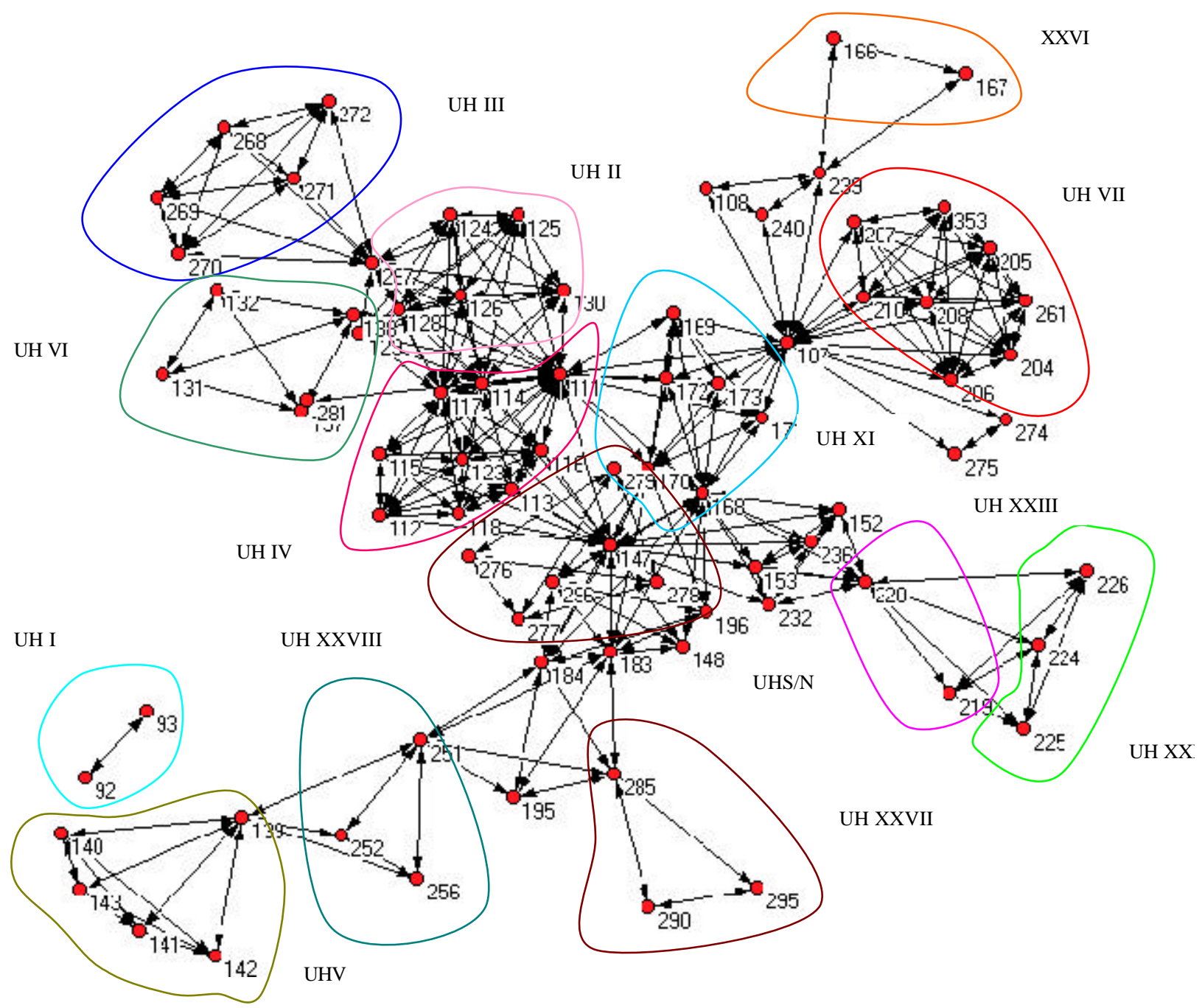

Referencias:

UH: unidad habitacional 